\section{Sea-ice minimum is not a one-off}

There is heated discussion over whether or not this year's seasonal sea-ice minimum in the Arctic constitutes a record (see go.nature.com/bmydx7 and, for example, go.nature. com/286mdp). But the debate misses the crucial point: this year's minimum is evidence that the unprecedented seasonal minimum of 2007 was not a one-off.

Continuous global satellite sea-ice observations began in 1972. A value for sea-ice coverage is retrieved from the surface microwave emission, using the different emission properties of water and ice. The sea-ice extent is conventionally defined as the sum of all data elements that have more than $15 \%$ ice cover.

Several remote-sensing groups work on this topic, using various methods and data from at least two different satellite instruments: the Advanced Microwave Scanning Radiometer - Earth Observing System (AMSR-E) on NASA's Aqua satellite and the Special Sensor Microwave Imager/ Sounder (SSMIS).

All of these groups agree that the seasonal 2011 minimum is very close to the 2007 minimum. That value was about $25 \%$ less than the previous low in 2005 , and almost $40 \%$ less than the climatological mean for the seasonal minimum (1979-2007). In autumn 2007, this value could be considered an outlier, caused by unusually warm weather over large parts of the Arctic Ocean.

However, the five seasonal minima since 2007 are the lowest on record. Although it is too early to speak of a trend, other observations, such as the thinning of Arctic sea ice over the past two decades, also suggest that the 2007 and 2011 minima are not single outliers. Christian Melsheimer, Georg Heygster, Justus Notholt

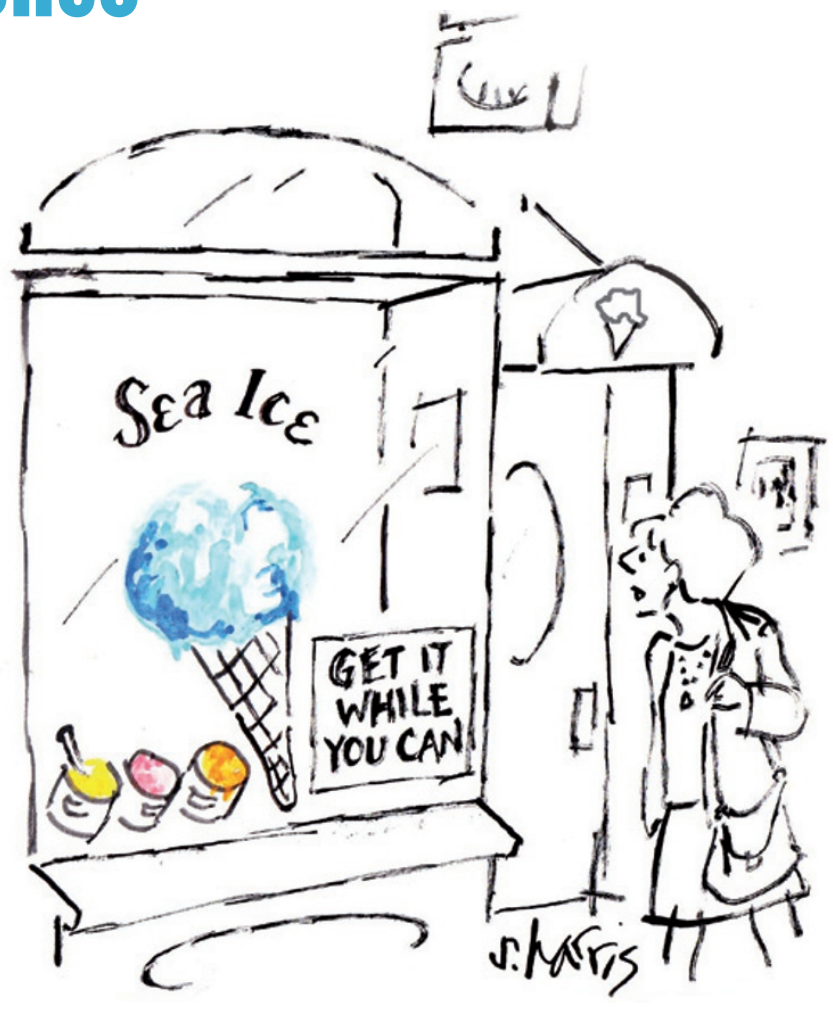

Institute of Environmental Physics, University of Bremen, Germany.

heygster@uni-bremen.de

\section{Vaccine research loses out}

The US government has spent an estimated $\$ 60$ billion on biodefence since the terrorist attacks of 11 September 2001 (Nature 477, 150-152; 2011). This is an unprecedented investment in biomedical research and infrastructure.

The value of capacitybuilding and spin-off discoveries that advance drug discovery and vaccine research should not be underestimated. However, suppose a fraction of this money had been used to accelerate vaccine research for existing diseases that pose a clear and present danger. In the case of HIV, tuberculosis and malaria - which together kill around 6 million people every year - we might have vaccines for all three by now.

Of the billions that are spent each year on combating infectious diseases using the tools we have, less than $2 \%$ is invested in vaccine research. The science is there to develop vaccines against these killer diseases, but the resources are not. A more balanced approach to allocating resources is needed.

Peter Hale The Foundation for Vaccine Research, Washington DC, USA.

peter.hale@vaccinefoundation.org Simon Wain-Hobson Institut Pasteur, Paris, France.

Robin A. Weiss University

College London, UK.

\section{The JASONs bought into the Vietnam War}

I was surprised that Ann Finkbeiner did not mention the JASONs' involvement in the war in Vietnam in the 1960s, in which they were far from independent (Nature 477, 397-399; 2011).

The JASONs, a secretive group of US defence science advisers, bought the Pentagon line that the problem was infiltration from North Vietnam. They proposed laying a carpet of anti-personnel weapons across the entire demilitarized zone, including gravel and spider mines, button

bomblets, and nail and cluster bombs. The US military replaced the 2.5-centimetre metal flechettes in the nail bombs with sharp slivers of plastic that Vietnamese physicians could not locate with X-rays.

As one critic said shortly before the war ended (D. Shapley Science 179, 459-505; 1973), the JASONs were "totally unaware that they're just being used by some little, puddin'-headed guy in the Pentagon".

Joseph Schwartz London, UK. josephschwartz@btinternet.com

\title{
Fallacy in costs of pollution control
}

You perpetuate a well-worn economic fallacy in arguing that tightening pollution regulations would help the economy because "money spent on reducing emissions does not disappear into a vacuum: pollution control is a business, too" (Nature 477, 249; 2011). As economist Frederic Bastiat pointed out in 1850 , “The error begins when the sacrifice itself is said to be an advantage because it profits somebody" (Essays on Political Economy Provost, 1874).

If it costs money to reduce pollution, that is because we must pay to divert people and equipment away from other activities that also benefit society. The benefits of pollution control may be worth the costs, but it is pure doublethink to claim that costs are benefits.

Neal Hockley Bangor University, Wales, UK. neal.hockley@univ.bangor.ac.uk

CONTRIBUTIONS

Correspondence may be sent to correspondence@ nature.com after consulting the author guidelines at go.nature.com/cmchno. Readers are also welcome to comment online: www.nature.com/nature. 